\title{
Formation of Necklace-Type Vortex System Upstream of a Gate Valve in Pipe Flow
}

\author{
Kyohei Shingai1, Teruyoshi Sadahiro ${ }^{2}$, Hidemi Yamada1 \\ ${ }^{1}$ Department of Mechanical and Energy Systems Engineering, Oita University, Oita, Japan \\ ${ }^{2}$ Department of Mechanical and Engineering, National Institute of Technology, Sasebo Collage, Sasebo, Japan \\ Email: yamada@oita-u.ac.jp
}

How to cite this paper: Shingai, K., Sadahiro, T. and Yamada, H. (2018) Formation of Necklace-Type Vortex System Upstream of a Gate Valve in Pipe Flow. Open Journal of Fluid Dynamics, 8, 133-140.

https://doi.org/10.4236/ojfd.2018.82010

Received: April 23, 2018

Accepted: June 2, 2018

Published: June 5, 2018

Copyright $\odot 2018$ by authors and Scientific Research Publishing Inc. This work is licensed under the Creative Commons Attribution International License (CC BY 4.0).

http://creativecommons.org/licenses/by/4.0/

\begin{abstract}
A gate valve is one of the main elements of a circular pipeline, but the flow characteristics around the gate valve are hardly known. In this study, clarification of the flow field in front of the gate valve model in a pipe flow via flow visualization and PIV analysis was attempted. As a result, four kinds of steady necklace-type vortex systems, 2-vortex, 4-vortex, 6-vortex and 8-vortex systems, were clearly observed in a Reynolds number between 290 and 2130. In addition, the main vortex was observed in the Reynolds number range between 2130 and 4870 with difficulty. On this account, both the center position and vorticity in the main vortex are presented against Reynolds number.
\end{abstract}

\section{Keywords}

Pipe Flow, Gate Valve, Vortex Formation, Flow Visualization, PIV Analysis

\section{Introduction}

A gate valve has a feature that the pressure loss when fully opened is small and the valve opening degree can be finely adjusted. The gate valve is one of the main elements of a circular pipeline. However, the flow pasts a gate valve and the resistance characteristics of a gate valve have not been investigated sufficiently.

Koram and Sparrow (1978) and Sparrow et al. (1980) reported heat transfer and pressure drop characteristics induced by an unsymmetric blockage element installed into the circular pipe [1] [2]. Oguri (1991) and Yamada and Katoh (1993) studied a flow-meter using a segmental blockage element, such as a gate valve [3] [4]. Yamada et al. (2015) also investigated flow field and loss coefficient produced by a gate valve model installed in a circular pipe [5]. They first showed that one necklace-type vortex is formed in front and moves over the gate valve 
model by using dye-method visualization. Recently, Alimonti (2014) reported an experimental characterization about pressure drop and flow rate of gate valves in vertical gas-liquid flows [6]. Lin et al. (2016) calculated influence of flashboard location on flow resistance properties and internal features of the gate valve model in rectangular pipes [7].

The flow resistance in the protrusion of various shapes installed into the pipe has been well studied. However, the flow field around a protrusion which is unaxisymmetric with circular pipe axis, e.g. a gate valve, in a circular pipe is not well-known. Particularly, excluding the study by Yamada et al., the flow field in front of the protrusion has hardly been investigated [5].

Therefore, our interest was focused on the flow field in front of the gate valve model in circular pipes. Particularly, in this paper the feature of the necklace-type vortex (vortex system, vortex position, and vorticity) was investigated by flow visualization and PIV analysis against a wide Reynolds number.

\section{Experimental Apparatus and Procedure}

The measuring circular pipe employed in this experiment lies in a water channel flow which is $400 \mathrm{~mm}$ in width and $400 \mathrm{~mm}$ in depth. Figure 1 shows the coordinate system and nomenclature in the circular pipe. The circular pipe is made of transparent acrylic with an internal diameter of $42 \mathrm{~mm}$ and a wall thickness of $4 \mathrm{~mm}$. An inlet long ellipse nozzle is attached in the entrance of the pipe to smooth the inflow. The radius of curvature of the gate valve model is $D / 2$ and the thickness is $t / D=0.1$. The height ratio of the gate valve model height to the pipe diameter is $h / D=0.6$. Therefore, the blockage ratio of the model front to the cross section is 0.5 . The gate valve model was attached in the position of $1700 \mathrm{~mm}$ from the nozzle exit. In the experiment, fine nylon particles with an average particle size of $50 \mu \mathrm{m}$ and a specific gravity of 1.03 were mixed in the water channel to visualize the flow. Then, the flow upstream of the gate valve model was irradiated by the laser light sheet, and was captured by using a high-speed camera. Conditions for shooting are shown in Table 1. The Reynolds number, $\operatorname{Re}\left(=U_{\mathrm{m}} \cdot D / v\right)$, was defined based on measuring the pipe diameter, $D$, and the averaged velocity, $U_{\mathrm{m}}$, which was determined by using a flow-meter installed in the downstream of the measuring pipe. The mean velocity of the flow

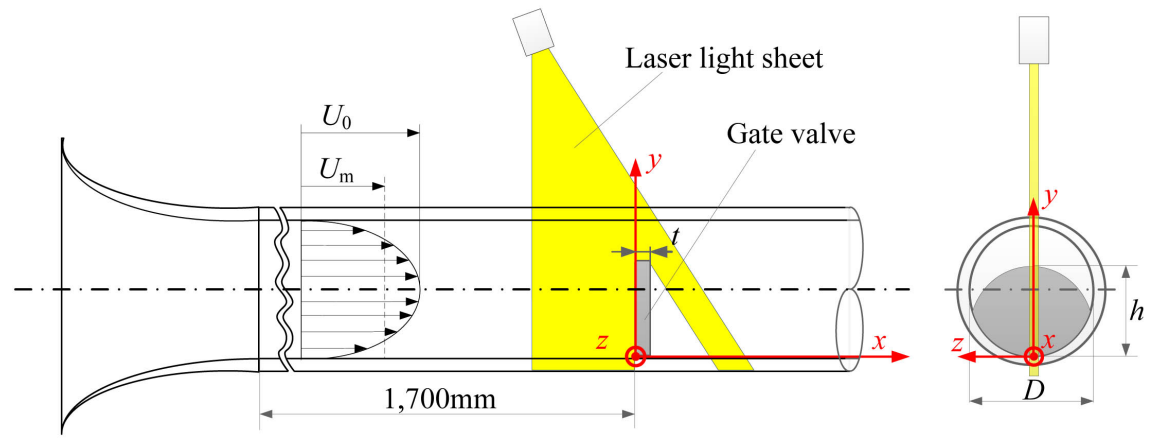

Figure 1. Experimental apparatus and nomenclatures. 
Table 1. Conditions for shooting.

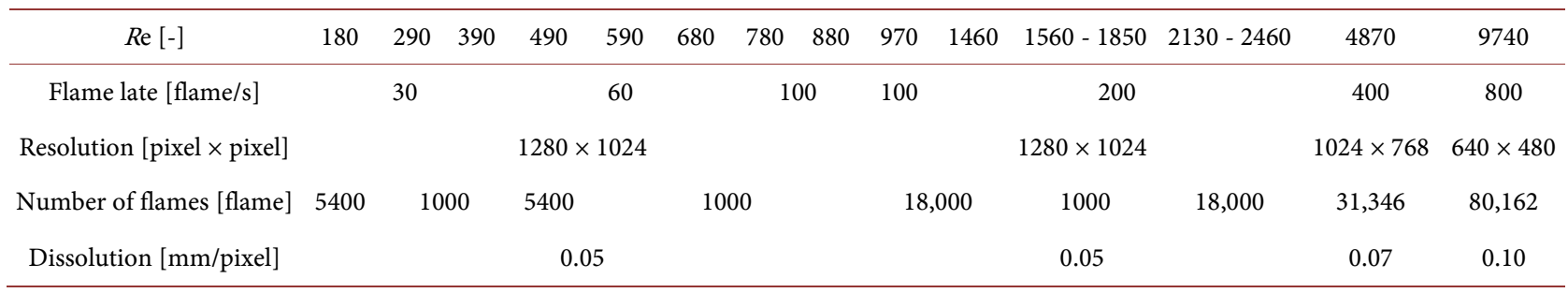

field was calculated by a PIV analysis based on the correlation method. Furthermore, the template size for pattern matching was decided as 31 pixels $\times 31$ pixels. Figure 2 shows the distribution of the mean velocity measured across the pipe without the gate valve model in each Reynolds number. Incidentally, uncertainty of velocity measured by the PIV in this research was about $6.5 \%$, which was obtained by comparing Poiseuille flow velocity and the obtained velocity.

\section{Experimental Results and Discussions}

It is well known that necklace vortices are formed in front of a three-dimensional obstacle mounted on a wall. Surprisingly, various vortex systems to be similar with the necklace vortex systems shown by Nakahara and Yamada [8] were also confirmed upstream of the gate valve model in this experiment. Therefore, we named the clockwise vortices as $\mathrm{V}_{1}, \mathrm{~V}_{2}, \mathrm{~V}_{3}, \mathrm{~V}_{4}$ upstream of the gate valve model, and called the counter clockwise vortices as $\mathrm{V}_{0}, \mathrm{~V}_{1}^{\prime}, \mathrm{V}_{2}^{\prime}, \mathrm{V}_{3}^{\prime}$ as shown in Figure 3(d). Incidentally, by visualizing the dye behavior invading into one vortex tube, Yamada et al. showed that the vortex in the case of the gate valve model is almost equal with the main vortex in ordinary necklace vortices [5]. Therefore, we decided to call the vortices observed in this experiment a necklace-type vortex system.

\subsection{Formation of Vortex System}

Figure 3 shows the path lines image upstream of gate valve model in each Reynolds number. These path lines images were made by mutually superposing consecutive particle-images of 800 . As shown in Figure 3, the steady necklace vortices were formed in the range of $R \mathrm{e} \leq 2130$. In the case of $R \mathrm{e}=290$, the flow field was regarded as a 2-vortex system, because the number of the steady vortices having different signs was 2. Accordingly, the flow field was regarded as a 4 -vortex system in $R \mathrm{e}=490$, as a 6-vortex system in $R \mathrm{e}=970$ and as an 8-vortex system in $R e=2130$. In the range of $R e \geq 2460$, the flow field became more unsteady with increasing Reynolds number. Although, the center position of the main vortex $V_{1}$ in $R e=2460$ and 4870 could be observed as well as the steady vortex system described above. Therefore, both formation and collapse of vortices may exist in the case of those Reynolds numbers. In the case of $R e=9740$, it was difficult to confirm the formation of a time-averaged vortex system.

Figure 4 shows the variation of the steady vortex system against the Reynolds number. As mentioned above, the steady flow field varied from a 2-vortexto an 


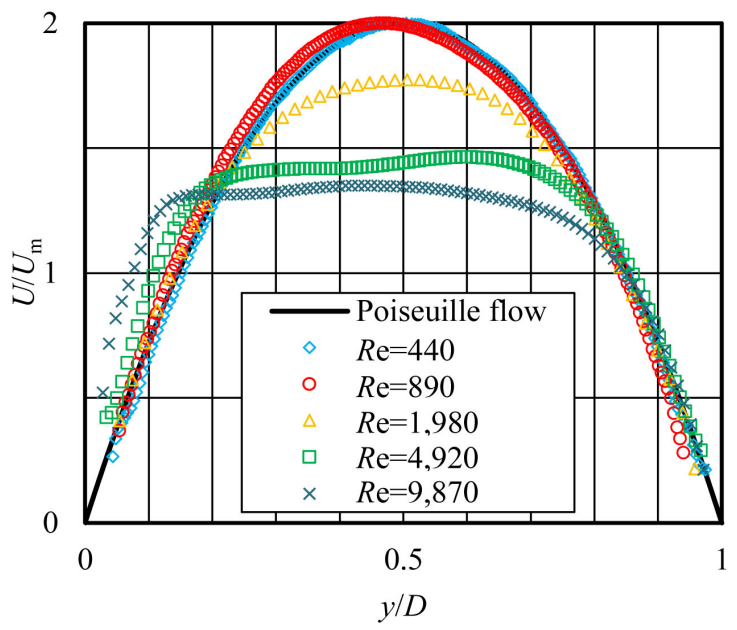

Figure 2. Velocity distribution in each Reynolds number without the gate valve model, measured in the position of $1700 \mathrm{~mm}$ downstream of the nozzle exit.

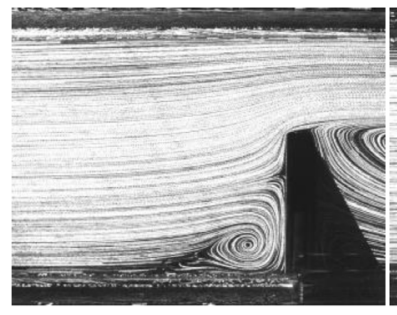

(a)

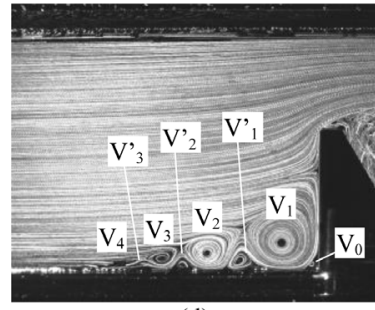

(d)

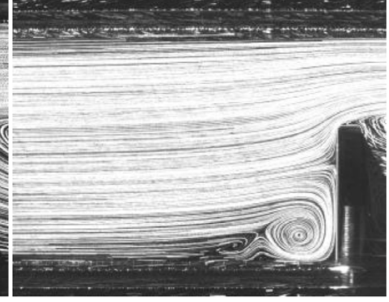

(b)

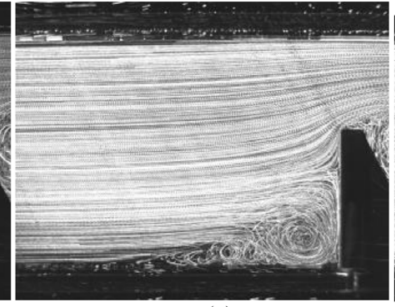

(e)

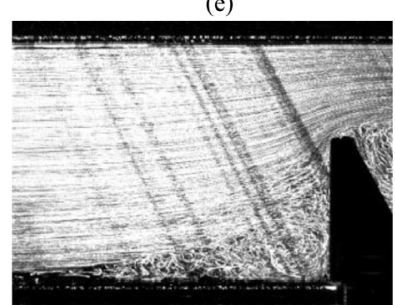

(g)

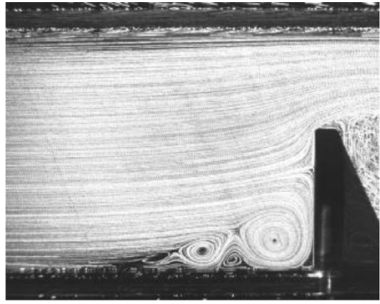

(c)

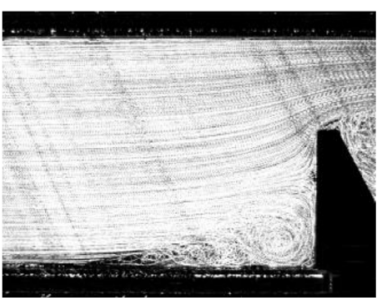

(f)

Figure 3. Visualization of necklace-type vortices by path lines: (a) $R e=290$; (b) $R e=$ 490; (c) $R e=970 ;(d) R e=2130 ;(e) R e=2460$; (f) $R e=4870$; and (g) $R e=9740$.

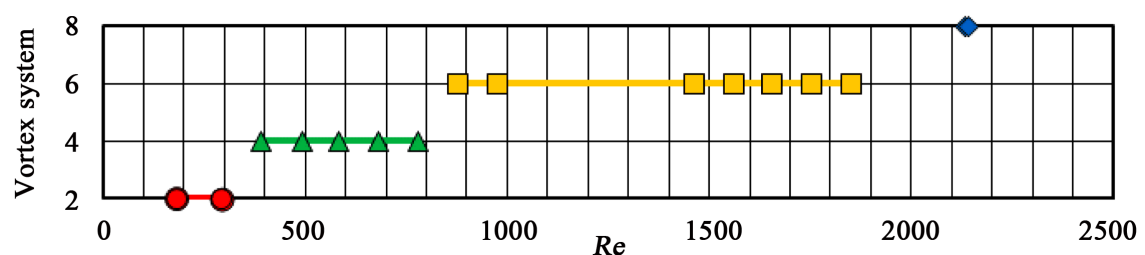

Figure 4. Classification of vortex system. 
8 -vortex system. The 2 -vortex system existed between $R e=180$ and 290 , the 4-vortex system existed between $R \mathrm{e}=390$ and 780, the 6-vortex system existed between $R e=880$ and 1850, and the 8-vortex system existed in $R e=2130$. Since the flow field was unsteady in $R e=2460$, the range of Reynolds number in which the steady 8 -vortex system appears is extremely small.

\subsection{Characteristics of Vortex System}

Figure 5 shows the ratio of the center point distance of the main necklace-type vortex, $\mathrm{V}_{1}$, to the circular pipe diameter, $D$. The $x$-direction distance from the gate valve model to the $\mathrm{V}_{1}$ center point is defined as $X_{\mathrm{V} 1}$, the height from the bottom wall of the circular pipe to the center point of the $\mathrm{V}_{1}$ is defined as $Y_{\mathrm{V} 1}$. The dashed line is the approximate line calculated by using the least squares method in the Reynolds number range drawn by the dashed line. $X_{\mathrm{V} 1} / D$ increased in the range of $R e \leq 500$, and gradually decreased, linearly, in the range of $R \mathrm{e}>500 . Y_{\mathrm{V} l} / D$ gradually decreased, linearly, until $R \mathrm{e}=4920$. Therefore, the center point of $\mathrm{V}_{1}$ may gradually approach the gate valve model, and the scale of $\mathrm{V}_{1}$ may gradually become smaller as Re increases. Figure 6 shows the stagnation point height $Y_{\mathrm{s}}$ which is the distance from the circular pipe bottom wall to the stagnation point. $Y \mathrm{~s} / D$ increased until $R \mathrm{e}=1000$, and gradually decreased as $R \mathrm{e}$ increases. Figure 7 shows the ratio of $\mathrm{V}_{1}$ center height $Y_{\mathrm{V} 1}$ to the stagnation point height $Y_{\mathrm{s}} . Y_{\mathrm{V} 1} / Y_{\mathrm{s}}$ also gradually decreased with increasing Reynolds number. However, $Y_{\mathrm{V} 1} / Y_{\mathrm{s}}$ might be regarded as a value of about 0.30 in the Reynolds number range between approximately 500 and 5000 .

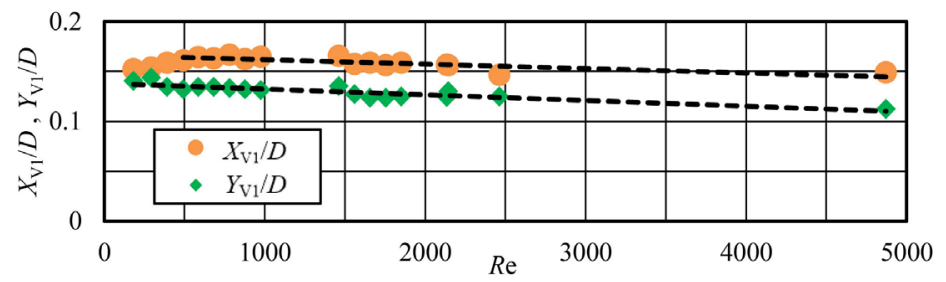

Figure 5. $\mathrm{V}_{1}$ center point distance.

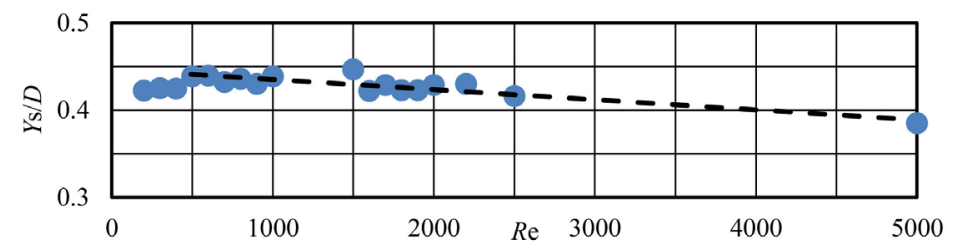

Figure 6. Stagnation point height.

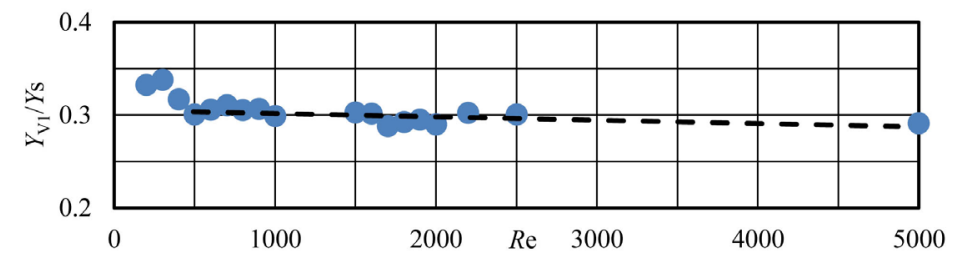

Figure 7. Ratio of $Y_{\mathrm{V} 1}$ to $Y$ s. 
Figures 8(a)-(c) show the contours of relative vorticity obtained from time-averaged velocity data calculated by the PIV analysis. The negative value represents a clockwise rotation. In $R e=970$, there was the vorticity contour corresponding with the 6-vortex system, though $\mathrm{V}_{3}$ could not be confirmed clearly as shown in Figure 8 (a). In $R e=4870$, the presence of unsteady main vortex was clarified by the contour of time-averaged vorticity, as shown in Figure 8(b). In $R e=9740$, the vortex formation could not be confirmed as well as the pass-lines image. However, there was a small negative vorticity observed in the turbulent region upstream of the gate valve model, as shown in Figure $8(\mathrm{c})$. Figure 9 shows the maximum relative vorticity in the $\mathrm{V}_{1}$ center point. The relative vorticity increased in proportion to the Reynolds number. However, the relative vorticity in the main vortex center may be constant in the range of $R e>2000$, because the maximum value of $\left(-D / U_{\mathrm{m}}\right) \Omega$ in $R \mathrm{e}=4870$ was about 70 as shown in Figure 8(b).

\section{Conclusions}

The existence of the necklace-type vortex systems produced upstream of the gate valve model $(h / D=0.6)$ in the circular pipe was observed by using the flow visualization and PIV analysis. As a result, the following considerations about the characteristic of necklace-type vortices were gained:

1) Vortex systems were observed from two vortices to eight vortices in the range of $R e \leq 2130$. In the range of $R e \geq 2460$, unsteady necklace vortices were formed.

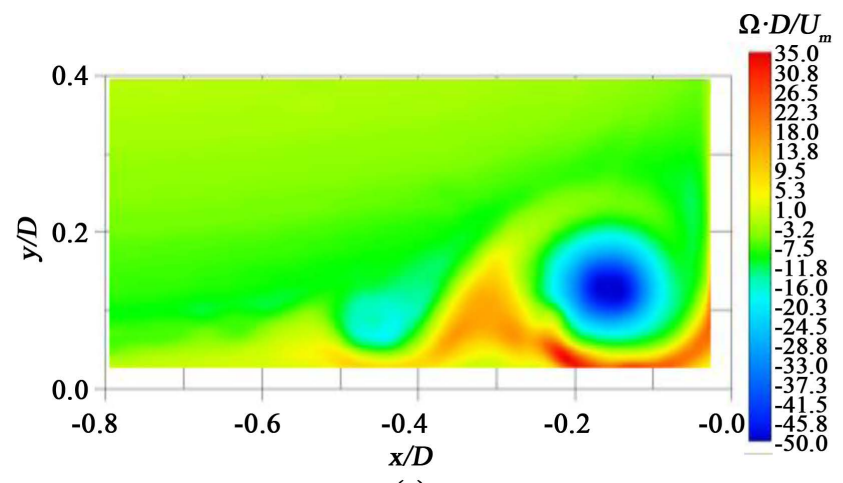

(a) (a)

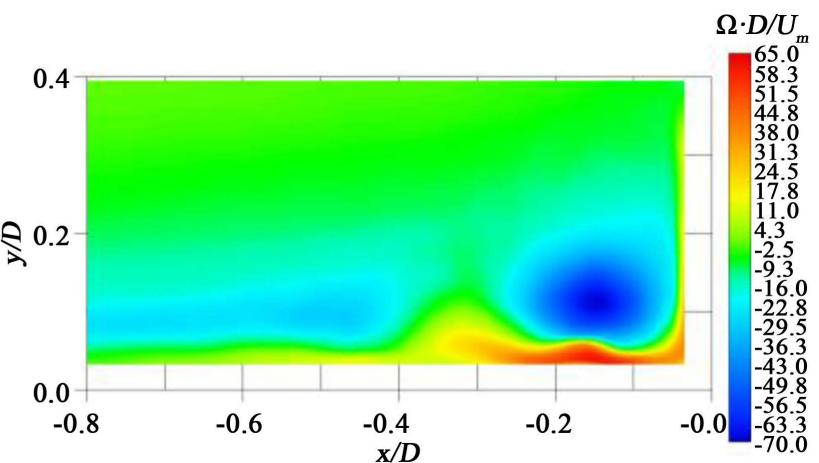

(b)

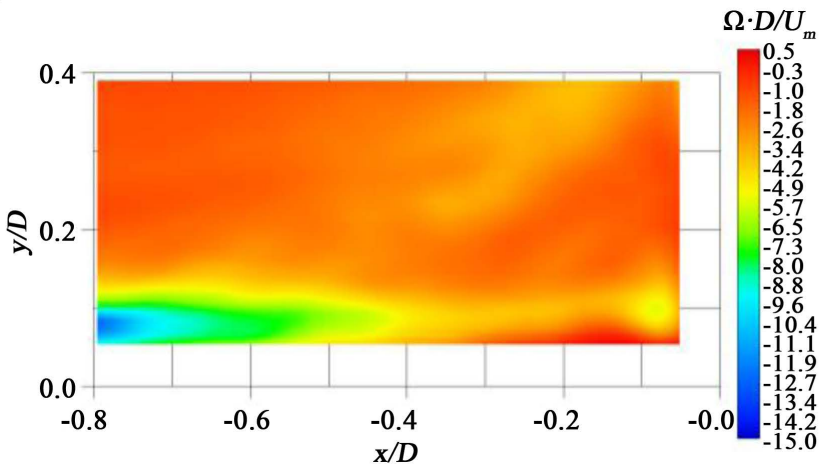

(c)

Figure 8. Contour of relative vorticity: (a) $R \mathrm{e}=970$, (b) $R \mathrm{e}=4870$, and (c) $R \mathrm{e}=9740$. 


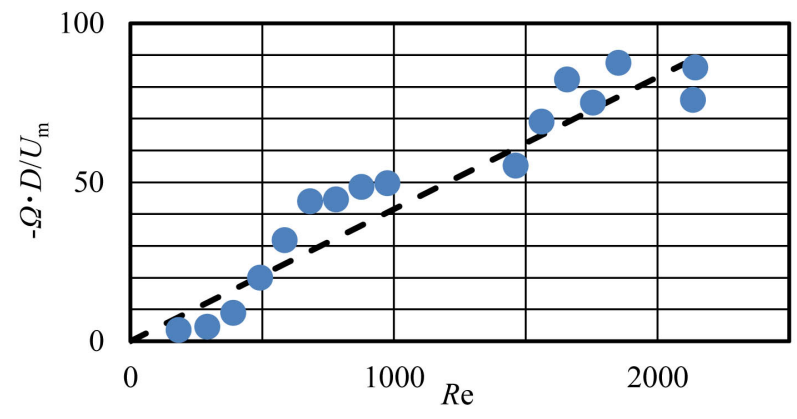

Figure 9. Vorticity distribution in $\mathrm{V}_{1}$ center point.

2) As the steady necklace-type vortices in the upstream region of the gate valve model, formation of a 2-vortex system in $R \mathrm{e}=180-290$, a 4-vortex system in $R \mathrm{e}=390-780$, a 6-vortex system in $R \mathrm{e}=880-1850$, and an 8-vortex system in $R \mathrm{e}=2130$ occurred.

3) In the case of $R \mathrm{e}>500, X_{\mathrm{V} 1} / D$ and $Y_{\mathrm{V} 1} / D$ gradually decreased linearly with increasing Reynolds numbers. Therefore, the center position of $\mathrm{V}_{1}$ approached the gate valve model as the Reynolds increased.

4) The relative vorticity at the center point of $V_{1}$ increased almost in proportion to the Reynolds number until about $R \mathrm{e}=2000$.

\section{References}

[1] Koram, K.K. and Sparrow, E.M. (1978) Turbulent Heat Transfer Downstream of an Unsymmetric Blockage in a Tube. Journal of Heat Transfer, 100, 588-594. https://doi.org/10.1115/1.3450861

[2] Sparrow, E.M., Koram, K.K. and Charmchi, M. (1980) Heat Transfer and Pressure Drop Characteristics Induced by a Slat Blockage in a Circular Tube. Journal of Heat Transfer, 102, 64-70. https://doi.org/10.1115/1.3244250

[3] Oguri, Y. (1991) Experimental Study on Segmental Flowmeters. The Japan Society of Mechanical Engineers, Series B, 57, 82-86. (In Japanese)

[4] Yamada, H. and Katoh, Y. (1993) Flow Rate Measurement Using Projecting Plate, Flow Measurement (FLOMEKO’93), KRISS, 256-260.

[5] Yamada, H., Nakahara, Y. and Tsuchiya, T. (2015) Flow Field through a Gate Valve Installed in a Circular Pipe and Loss Coefficient. The Japan Society of Mechanical Engineers, 81, 1-13. (In Japanese)

[6] Alimonti, C. (2014) Experimental Characterization of Globe and Gate Valves in Vertical Gas-Liquid Flows. Experimental Thermal and Fluid Science, 54, 259-266. https://doi.org/10.1016/j.expthermflusci.2014.01.001

[7] Lin, Z., Ma, G., Cui, B., Li, Y., Zhu, Z. and Tong, N. (2016) Influence of Flashboard Location on Flow Resistance Properties and Internal Features of Gate Valve under the Variable Condition. Journal of Natural Gas Science and Engineering, 33, 108-117. https://doi.org/10.1016/j.jngse.2016.05.025

[8] Nakahara, Y. and Yamada, H. (2015) Visualization of a Laminar Necklace Vortex System in Front of a Vertical Rectangular Plate on a Ground Wall. Journal of Flow Control, Measurement \& Visualization, 3, 75-85. https://doi.org/10.4236/jfcmv.2015.32008 


\section{Nomenclatures}

$x$. Distance measured from front surface of gate valve [m]

y. Distance measured along asymmetry line of gate valve model from circular pipe bottom $[\mathrm{m}]$

$u: \quad x$-direction velocity component $[\mathrm{m} / \mathrm{s}]$

v. $\quad y$-direction velocity component $[\mathrm{m} / \mathrm{s}]$

$U_{\mathrm{m}}$ : Flow velocity averaged in cross-sectional area $[\mathrm{m} / \mathrm{s}]$

$U_{0}$ : Maximum velocity in cross-sectional area $[\mathrm{m} / \mathrm{s}]$

Re: Reynolds number $\left(=U_{\mathrm{m}} \cdot D / v\right)$

$D$ : Diameter of circular pipe $[\mathrm{m}]$

t. Thickness of gate valve model [m]

$h$ : Height of gate valve model [m]

$X_{\mathrm{V} 1}: X$-direction distance from gate valve model to $\mathrm{V}_{1}$ center point [m]

$Y_{\mathrm{V} 1}: y$-direction height from circular pipe wall bottom to $\mathrm{V}_{1}$ center point $[\mathrm{m}]$

$Y$ s: $y$-direction height from circular pipe wall bottom to stagnation point [m]

$\Omega:$ Vorticity $\left(=\frac{\partial v}{\partial x}-\frac{\partial u}{\partial y}\right)[1 / \mathrm{s}]$

v: Kinematic viscosity $\left[\mathrm{m}^{2} / \mathrm{s}\right]$ 